\title{
Tetra-Phosphonate Calix[4]Pyrrole Cavitands as Multitopic Receptors for the Recognition of Ion- pairs
}

\author{
Moira Ciardi ${ }^{\dagger}$, Albano Galán ${ }^{\dagger}$ and Pablo Ballester ${ }^{\star \dagger \ddagger}$ \\ †Institute of Chemical Research of Catalonia (ICIQ), Avda. Països Catalans 16, 43007 Tarragona \\ (Spain) \\ ‡Catalan Institution of Research and Advanced Studies (ICREA), Passeig Lluís Companys 23, \\ o8018 Barcelona (Spain)
}

\begin{abstract}
The synthesis, structural characterization and binding properties of two unprecedented multitopic receptors for ion-pair recognition are described. We isolated two of the six possible diastereomeric deep cavitand receptors resulting from the installation of four phosphonate groups at the upper rim of a calix[4]pyrrole-resorcin[4]arene hybrid scaffold. The isolated tetra-phosphonate receptors display either three (iooo) or four (oooo) of their $\mathrm{P}=\mathrm{O}$ groups oriented away from the deep and functionalized aromatic cavity. In contrast to analogous tetra-phosphonate resorcin[4]arene cavitands, the fourteen-membered macrocyclic rings that contain the $\mathrm{P}=\mathrm{O}$ groups in the tetraphosphonate calix[4]pyrrole cavitands are conformationally flexible, always adopting a conformation locating the phenyl substituents in equatorial position. The tetra-phosphonate calix[4]pyrroles exhibited larger affinity constants than the previously reported bis-phosphonate calix[4]pyrrole counterparts in the complexation of both tetramethylphosphonium and octylammonium chloride salts in non-polar solvents. We demonstrated that the iooo diastereoisomer was able to function as a multitopic receptor for organic chloride salts by switching the geometry of the 1:1 ion-paired complex from receptor-separated to close-contact depending on the quaternary or primary nature of the cobound organic cation. The ion-paired 1:1 complexes formed between the diastereomeric receptors and organic chloride salts were studied and thermodynamically characterized in solution. The determined stability constant values were compared with those obtained for the bis-phosphonate counterparts. The structure of the TMPCl $\subset$ 7iooo complex was determined by X-ray structure and its formation was also evidenced in the gas phase.
\end{abstract}

Introduction

During recent years, the design and synthesis of receptors capable of recognizing ion-pairs has attracted increasing interest. , Simple ditopic ion-pair receptors, so-called heteroditopic receptors, contain single sites for the simultaneous recognition of the anion and the cation. On the other hand, multitopic receptors for ion-pairs contain more than one binding site for either the cation or the anion. It is widely accepted that both heteroditopic and multitopic receptors exhibit improved properties (affinity and selectivity) for the complexation of ionpairs when compared to monotopic counterparts capable of binding a single cation or anion. , Cooperative interactions between cobound ions (electrostatic) and cooperative allosteric effects induced by the initial binding of one of the ions are claimed as being responsible for the enhancement in binding properties. In addition, the complexation of the counter-ion of the targeted ion is also described as a way of reducing binding interferences arising from ion- 
pairing and solvation effects. , However, true cooperativity provided by the simultaneous complexation of the cation and the anion is not easy to assess because the formulation of ionpair binding requires the consideration of several equilibria and involves the multivariable fit of the titration data to elaborated mathematical algorithms.

For the sake of simplicity, the values frequently encoun-tered in the literature and the values reported here for the stability constants of ion-pair complexes correspond to experimental binding constants; Ka,exp, which are determined using a simple 1:1 theoretical binding model and thus are reported in $\mathrm{M}-1$ units.

An interesting example of multitopic ion-pair receptors derived from a calix[4]pyrrole scaffold has been recently described by Sessler et al. , In this work, crown ethers of different sizes are covalently linked to the meso-aryl substituents of "two-wall" aryl extended calix[4]pyrrole resulting in the formation of stable ion-pair complexes with alkali metal ( $\mathrm{K}+$ and $\mathrm{Cs}+$ ) fluoride salts, both in the solid state and in solution. Depending on the cobound alkali metal, the cation is coordinate to the oxygen atoms of the crown $(\mathrm{K}+)$ or included in the cone-shaped cavity opposite to the bound anion ( $\mathrm{Cs}+$ ). In more elaborated designs, one unit of 1,3-alternate calix[4]crown-5 was bridged between the two para position of the meso-aryl substituents of a "two-wall" calix[4]pyrrole with ethylenedioxy spacers (Figure 1a). Receptor 1 consist of one anion binding site and, potentially, three cation recognition sites displaying different affinities for different alkali metal cations.

Figure 1.

Our group, recently reported the synthesis of three dia-stereomeric bis-phosphonate cavitands 2 based on the $\alpha, \alpha, \alpha, \alpha$-isomer of a "four-wall" aryl extended ca-lix[4]pyrrole tetrol scaffold (Figure $1 \mathrm{~b}$ ). The diastereoiso-mers differ in the relative spatial orientation of the $\mathrm{P}=\mathrm{O}$ groups installed at their upper rim. Owing to the reduc-tion of conformational flexibility imposed by the bridging phosphonates, these cavitands possess a permanent deep aromatic cavity closed at one end by the calix[4]pyrrole core.

Bis-phosphonate cavitands 2 qualify as multitopic recep-tors for ion pairs. They feature a single coordination site for the anion, the calix[4]pyrrole core, but two different binding sites for the organic cation. One of the cation binding sites is provided by the electron-rich cup defined by the four pyrrole rings at the lower rim of the receptor and opposite to the bound anion. The other binding site for the cation is defined by a cleft generated between the bridging phosphonate groups at the upper rim. In this latter binding mode the cation is in close-contact to the deep included bound anion. We demonstrated that, in dichloromethane solution, the diastereoisomers having one or two $\mathrm{P}=\mathrm{O}$ groups pointing towards the center of this cavity, 2io and $2 \mathrm{ii}$ isomers respectively ( $\mathrm{o}=\mathrm{out}, \mathrm{i}=\mathrm{in}$; indicates the orientation of the $\mathrm{P}=\mathrm{O}$ groups with respect to the cavity) preferentially bound tetraalkylammonium chloride salts with a closecontact arrangement of the ions (Figure $1 \mathrm{~b}$ right). This is due to the existence of elec-trostatic interactions between the converging $\mathrm{P}=0$ group/s and the cobound ammonium cation included in the cavity at the upper rim. Conversely, the diastereoiso-mer with the two $P=0$ groups outwardly directed with respect to the cavity prefers to bind tetraalkylammonium chloride salts with a receptor separated arrangement of ions (Figure $1 \mathrm{~b}$ left), thus placing the cobound ammonium in the cup-like cavity at the lower rim opposite to the bound chloride. 
When four phenyl phosphonate groups are introduced at the upper rim of resorcin[4]arene 3 (Scheme 1), up to six tetra-phosphonate diastereoisomers 4 can be pro-duced. , , The theoretical statistical distribution of iso-mers is 1 [oooo]:1[iiii]:2[ioio]:4[iiio]:4[iioo]:4[iooo] favoring those with one or more phenyl group inwardly oriented.18 Conversely, molecular modelling studies disfavored the convergence of two or more phenyl groups in the cavity of related phosphonito cavitands (iioo, ioio and iooo isomers).

Scheme 1.

Experimentally, the reaction of resorcin[4]arene 3 with dichlorophenylphosphane 5 in acetone solution and in presence of triethylamine afforded the 4iooo isomer, with three phenyl groups oriented towards the cavity interior as the main component of the crude reaction.18 The isomers with four (4iiii) and three phenyl groups (4iiio) outwardly oriented with respect to the cavity were not even detected. In toluene solution, the use of 1 equivalent of $\mathrm{N}$ methylpyrrolidine modified the course of the reaction and resulted in the almost exclusive production of the 4 iiii isomer in a $51 \%$ isolated yield most likely due to the template effect of the pyrrolidine guest.19 The different isomers of the tetra-phosphonate cavitands 4 with inwardly oriented $\mathrm{P}=\mathrm{O}$ groups are remarkable receptors for linear alcohols, , N-methyl ammonium salts, primary ammonium salts, 22 , and cesium cations. 22 They are also used for the construction of selective sensor devices for molecular recognition applications in solidliquid and solid-gas interfaces. These findings in combination with our previous experience in the synthesis of bis-phosphonate cavi-tands 2 derived from aryl extended calix[4]pyrroles prompted us to prepare tetra-phosphonate calix[4]pyrrole cavitands.

Scheme 2.

Herein, we describe the upper rim functionalization of the calix[4]pyrrole-resorcin[4]arene hybrid 6 (Scheme 2) with four phosphonate groups providing two unprece-dented diastereomers. We also disclose the superior binding properties of the calixpyrrole tetraphosphonate cavitands 7 in the complexation of ammonium and phosphonium ion-pairs compared to the structurally closely related bis-phosphonate counterparts 2 . The 7iooo diastereoisomer acts as a multitopic ion receptor switching from a receptor separated binding mode of the ion-pair to a close-contact mode when the cobound tetraalkylammonium cation is replaced by a primary alkylammonium counterpart.

\section{Results and Discussion}

Synthesis. We first attempted the installation of four phosphonate bridges at the upper rim of the methyl-footed octol $\alpha, \alpha, \alpha, \alpha-6 a$ using the same synthetic proce-dure reported for the preparation of the bis-phosphonate cavitands 2.16 The treatment of $\alpha, \alpha, \alpha, \alpha-6$ a with five equivalents of dichlorophenylphosphane 5 led to an insoluble and intractable crude reaction mixture. Recently, we reported the synthesis of $\alpha, \alpha, \alpha, \alpha-6 b$, a lipophilic version of $6 a$, as parent compound in the preparation of a series of deep cavitands having four orthodisubstituted aryl bridging groups. These molecules exhibited excellent solubility in most 
organic solvents. For this reason, we selected octol $6 \mathrm{~b}$ as a suitable aryl-extended calix[4]pyrrole alternative for the installation of the bridging phosphonates. The room temperature reaction of the lipophilic octol $\alpha, \alpha, \alpha, \alpha-6 b$ and dichlorophenylphosphane 5 ( 5 equiv) in THF solution in the presence of triethylamine for $2 \mathrm{~h}$ produced a crude mixture in which at least two of the six possible tetra-phosphonate diastereoisomers 7 were present. The two pure stereoisomers 70000 and 7iooo were isolated by semipreparative HPLC (Spherisorb silica $250 \times 20 \mathrm{~mm}, 5 \mu \mathrm{m}$ ) using hexanes/CH2Cl2 60:40 as eluent. The isomers were further purified by crystallization from acetonitrile and obtained in overall yields of 3 and $9 \%$ respectively.

We also prepared the tetra-methylene bridged cavitand 8 from the reaction of $6 \mathrm{~b}$ with chlorobromomethane as previously reported.27 This compound was used as a refer-ence system in the binding experiments with ion-pair salts.

Configurational Assignment and Structural Charac-terization. The configurational assignment of the two isolated tetra-phosphonate stereoisomers was performed by combining the data provided by their $1 \mathrm{H}$ and 31P NMR spectra with the analysis of single crystal X-ray diffraction data of one of them (70000) and of the complex with PMe4Cl of the other (7iooo).

Figure 2.

The $1 \mathrm{H}$ NMR spectrum of the first tetra-phosphonate cavitand that eluted from the semipreparative HPLC column exhibited sharp proton signals in a number that was consistent with a C4v symmetry, a clear diagnostic of either the iiii or the oooo isomers (Figure 2). Also consistent with a C4v symmetry, the 31P NMR spectra of the compound revealed the existence of a unique phosphorus signal resonating at $\delta=13.7 \mathrm{ppm}$. By means of 1D and 2D NMR experiments it was possible to assign all proton signals but not the unequivocally configuration of the $\mathrm{P}=0$ groups. In the bis-phosphonate series 2 , we observed that $\mathrm{P}=0$ groups directed away from the cavity had phosphorus atoms resonating at higher field, 13.2 ppm for 200 and $14.2 \mathrm{ppm}$ for $2 \mathrm{ii} .16$ The $\delta$ measured for the phosphorus atom of the first isolated tetra-phosphonate isomer $(\delta=13.7 \mathrm{ppm})$ was exactly in the middle of this range.

While studying the structural features of the series of diastereoisomers 2 (bis-phosphonate cavitands), we learned that the orientation of the $\mathrm{P}=0$ group with respect to the deep aromatic cavity had a negligible effect on the chemical shift values of the protons in the phenyl groups attached to the $P$ atoms. This is because, as depicted in Figure 3 , the fourteenmembered phosphocine ring of the calix[4]pyrrole phosphonate cavitands is conformationally more flexible than the eight-membered analogue in the resorcin[4]arene phosphonates 4 (See ESI). Simple molecular modelling calculations (MM3) performed on a mono-phosphonate bridged calix[4]pyrrole cavitand showed that the phosphocine ring adopted two different low energy conformations, boat-chair and boat-twistboat, in response to the relative orientation of the $\mathrm{P}=\mathrm{O}$ group with respect to the aromatic cavity. Interestingly, in both of them, the phenyl group is oriented in an equatorial position pointing away from the aromatic cavity. This 
eliminates the possibility of relating the chemical shifts values of the phenyl protons to the orientation exhibited by the $\mathrm{P}=\mathrm{O}$ group to which it is attached. The $\mathrm{X}$-ray structures previously described for the three stereoisomeric bis-phosphonate 2 testified the exclusive existence, in the solid-state, of phosphocine rings having equatorial phenyl groups, that is a boat-chair conformation for $\mathrm{P}=\mathrm{O}(\mathrm{i})$ and a boat-twistboat conformation for $\mathrm{P}=\mathrm{O}(\mathrm{O})$ bridges.

Figure 3.

Single crystals from the first eluted stereoisomer suitable for $\mathrm{X}$-ray diffraction grew from acetonitrile solution. The analysis of the diffraction data revealed that the isolated tetraphosphonate was the 70000 stereoisomer (see ESI for the computed energies of the acetonitrile inclusion complexes of the two stereoisomers with $\mathrm{C} 4$ symmetry $\mathrm{CH} 3 \mathrm{CN} \subset 7$ iiii and $\mathrm{CH} 3 \mathrm{CN} \subset 70000$ ). In the solid state, the 70000 cavitand featured $\mathrm{C} 4$ symmetry with the lone pairs of four of the eight bridging oxygen atoms inwardly di-rected towards its aromatic cavity providing an example of inherently chiral molecule. The cyclochiral conformer shown is defined to have $\mathrm{M}$ axial chirality by assigning priority to the oxygen atom with the lone pairs directed towards the cavity. 27 Both cycloenantiomers were ob-served in the crystal lattice. The fourteen-membered phosphocine rings adopted a boat-twistboat confor-mation analogous to the one observed also in the solid-state for the bis-phosphonate 200.16 Probably, when the oxygen atoms of the outwardly oriented $\mathrm{P}=\mathrm{O}$ group are moved to the axial position, they are forced into the face of the pyrrole ring. In order to minimize this repulsion, the $\mathrm{P}=\mathrm{O}$ oxygen atom rotates, the unshared electron pairs of four of the eight phenolic oxygen atoms face inward and the phosphocine ring adopts a boat-twistboat conformation.

Figure 4.

The two dimensions of the aromatic cavity become al-most identical ( $7.5 \AA$ between adjacent P atoms).

In the cyclochiral conformation adopted by the 70000 stereoisomer the protons $\mathrm{Hb}, \mathrm{Hb}^{\prime}$ and $\mathrm{Hc}, \mathrm{Hc}^{\prime}$ are diastereotopic, whereas in the $1 \mathrm{H}$ NMR spectrum of the cavitand (Figure 2) they did not resonate as separated signals. This observation suggested that in solution and at room temperature the interconversion between the two cycloenantiomers was occurring at a rate that is fast on the chemical shift NMR timescale explaining why the $1 \mathrm{H}$ NMR spectrum is consistent with a C4v symmetry.

Figure 5 shows selected regions of the $1 \mathrm{H}$ and 31P-decoupled $1 \mathrm{H}$ NMR spectra of the second eluted tetra-phosphonate diastereoisomer. The cavitand structure had a reduced symmetry producing more complex NMR spectra. A careful analysis of the number of resonances of the phosphorus atoms and protons led to the ascription of Cs symmetry, diagnostic of the 7iooo and 7iiio isomers. Because of uneven NOE enhancements of the signals by decoupling and long longitudinal relaxation times, the 31P NMR spectra were not suitable for integration. However, qualitatively it can be stated that three of the four phosphorous signals resonated at higher field. As commented above in the bis-phosphonate cavitand series $2, \mathrm{P}=0$ groups directed 
away from the cavity had phosphorus atoms resonating at higher field. Taken together, these results allowed the tentative assignment of this second isomer as 7iooo.

Figure 5.

We assigned the more upfield shifted signal $(\delta=6.1 \mathrm{ppm})$ of the $\beta$-protons to the pyrrole unit involved in the four-teen-membered phosphocine ring having the inwardly oriented $\mathrm{P}=0$ group. The upfield shift experienced by these protons must be produced by the phenyl substitu-ent at the phosphorus atoms located in equatorial posi-tion and facing the pyrrole ring (Figure 3 ). The high up-field shifts experienced by the aromatic protons $\mathrm{HI}$ and $\mathrm{Hn}$ are also consistent with an inward orientation of the bridging $\mathrm{P}=\mathrm{O}$ group. The configurational assignment of the 7iooo stereoisomer was corroborated by solving the $\mathrm{X}$-ray structure of its complex with $\mathrm{PMe} 4 \mathrm{Cl}$ (vide infra).

Binding studies with ammonium/phosphonium ion-pairs. We evaluated the newly prepared tetra-phosphonate cavitands 70000 and 7iooo as multitopic receptors for ion-pairs. We selected tetramethylphosphonium chloride $(9, \mathrm{TMPCl}$, Figure 6$)$ as a target ion-pair owing to its increased solubility in dichloromethane solution compared to tetramethylammonium chloride.

Figure 6.

In dichloromethane solution at $\mathrm{mM}$ concentration, both the TMPCl and its complexes with the cavitands are ex-pected to be almost completely ion-paired. The interac-tion of the two stereoisomers 7 with $\mathrm{TMPCl}(9)$ in $\mathrm{CD} 2 \mathrm{Cl} 2$ solution was probed using $1 \mathrm{H}$ and $31 \mathrm{P}\{1 \mathrm{H}\} N \mathrm{NMR}$ in separated titration experiments. The addition of 0.5 equivalents of salt 9 to a millimolar $\mathrm{CD} 2 \mathrm{Cl} 2$ solution of 70000 produced separated proton and phosphorous signals for the free and bound cavitand in the corresponding NMR spectra. When 1 equivalent of 9 was added only the signals assigned to bound 70000 were observable (Figure 7a). Taken together, these observations indicated that the chemical exchange between free and bound phosphonate cavitand was slow on the $1 \mathrm{H}$ and 31P NMR chemical shift timescales and that the magnitude of the stability constant for the $9 \subset 70000$ complex was greater than $104 \mathrm{M}-1$.

The large downfield shift experienced by the pyrrole NH protons ( $\mathrm{Ha} \mathrm{a}^{\prime} \delta=4.15 \mathrm{ppm}$ ) upon chloride binding indi-cated the formation of hydrogen bonding interactions, which required the inclusion of the chloride in the ca-lix[4]pyrrole deep aromatic cavity. The 31P $\{1 \mathrm{H}\}$ NMR spectrum revealed that the phosphorus signal assigned to the $\mathrm{P}=0$ groups in the bound receptor moved slightly upfield ( $\Delta \delta=-1.49 \mathrm{ppm}$ ) with respect to the free receptor. Likewise, the phosphorus signal of the TMP cation in the 9 ?970000 complex was also shifted upfield $(\Delta \delta=$ - 4.0 ppm, Figure S9). A 2D ROESY experiment (Figure S10) showed close-contact cross-peaks between the methyl protons of the TMP cation and the $\beta$-pyrrole protons of the $70000\left(\mathrm{Hb}^{\prime}\right)$. This finding suggested a preferential location of the TMP cation in the electron-rich shallow 
bowl of the calixpyrrole opposite to the bound chloride resulting in a $9 \subset 70000$ complex displaying host-separated ion-pair geometry.

Figure 7.

The complexation of TMPCl with the 7iooo stereoisomer was also probed using NMR spectroscopy (Error! Reference source not found.c). The obtained results demonstrated that the kinetic and thermodynamic behavior of the binding process was comparable to those described for 7000 (See Supporting Information). Previous work with the bis-phosphonate series of stereoisomers $2^{\text {Error! Bookmark }}$ not defined. evidenced that the presence of one or two $\mathrm{P}=\mathrm{O}$ groups inwardly directed led to a switching of the ion-pair arrangement in the complex. In short, the ion-pair was bound with receptor separated binding geometry by 200 but preferentially with close contact arrangement by zii and 2io. The complexation induced shifts $\left({ }^{1} \mathrm{H}\right.$ and $\left.{ }^{31} \mathrm{P}\left\{{ }^{1} \mathrm{H}\right\}\right)$ experienced by the bound TMP cation in complexes $\mathbf{9} \subset 70000$ and $\mathbf{9} \subset$ 7iooo cation were completely analogous. Moreover, a 2D ROESY experiment performed on the $9 \subset 7$ iooo complex demonstrated exclusive intermolecular contacts between the TMP cation and the $\beta$-pyrrole protons (Figure Si1). We concluded that both tetra-phosphonate stereoisomers 70000 and 7iooo recognized the TMPCl salt displaying a host-separated arrangement of the ions. In summary, the inward orientation of one $\mathrm{P}=\mathrm{O}$ group did not produce the switching of the ion-pair binding mode for the tetra-phosphonate diastereosiomers 70000 and 7iooo binding TMPCl.

Figure 8 .

The hydrogen bonding interaction and the deep inclusion of the chloride proposed for the $9 \subset 7$ iooo complex formed in solution was fully supported by the X-ray structure of the complex in the solid state (Figure 8). Unfortunately, the packing of the crystal showed a columnar motif, which did not provide unambiguous evidence of the ion-pair arrangement in such complex. It was rewarding to observe that in the solid-state the phosphocine rings in the $9 \subset 7$ iooo adopted the two different conformations expected as a function of the relative orientation of the $\mathrm{P}=\mathrm{O}$ group with respect of the cavity (boatchair for $\mathrm{P}=\mathrm{O}(\mathrm{i})$ and boat-twistboat conformer for $\mathrm{P}=\mathrm{O}(\mathrm{o})$ bridges $)$. As discussed above, in both ring conformations the phenyl substituent occupies an equatorial position. The formation of anionic $[\mathrm{Cl} \subset 70000]^{-}$and cationic $\left[\mathrm{TMP} \subset 70000^{\circ} \mathrm{CH}_{3} \mathrm{CN}\right]^{+}$complexes was also evidenced in the gas-phase through the detection of the corresponding ion peaks and their expected isotopic distributions using ESI-MS with negative and positive mode, respectively, to analyze a solution containing the tetraphosphonate cavitand and TMPCl (See Supporting Information).

We used isothermal titration calorimetry experiments to assess accurately the stability constant values for the $9 \subset_{7000}$ and $9 \subset 7$ iooo complexes in $\mathrm{CH}_{2} \mathrm{Cl}_{2}$ solution (See Supporting Information). At the concentrations required for the accurate calculation of the stability constants of the complexes, the heat released (0.3-0.5 ? $\mathrm{cal}$ ) after each injection of TMPCl to a solution of 7 was small, close to the detection limit of the calorimeter, and of the same order of the heat released by the simple dilution of the injected salt. These limitations are inherent to the systems under study and complicated the measurement of reliable data. Nevertheless, we obtained a reasonable fit of the integrated heat data, after subtracting the heat of dilution, to theoretical binding isotherms for the formation of 1:1 complexes (SI). The binding curves were mono-sigmoidal and showed an inflexion point centered at a molar ratio [9]/[Receptor] close to 1 . As already mentioned, we considered that in $\mathrm{CH}_{2} \mathrm{Cl}_{2}$ solution both the salt and the complex are ion-paired, thus a 1:1 binding model, although not ideal, is suitable for the mathematical analysis of titration data. The values calculated for the stability constant of the different complexes, the free energies of binding and their associated enthalpy and entropy terms are summarized in Table 1.

Table 1.

The complexation of TMPCl by the receptor series 7 was both enthalpically and entropically favorable. The strong and favorable entropic component measured for the two complexation processes suggested 
that solva-tion/desolvation effects must play a crucial role in bind-ing. In order to verify the ratio between the stability constant values determined for the $9 \subset 70000$ and $9 \subset 7$ iooo complexes using ITC experiments, we performed a pairwise competitive binding experiment. We analyzed a $\sim 1 \mathrm{mM} \mathrm{CD} 2 \mathrm{Cl}_{2}$ solution containing a close to equimolar amount of the two tetra-phosphonate receptors and TMPCl using ${ }_{1} \mathrm{H}$ and ${ }_{31} \mathrm{P}\{1 \mathrm{H}\}$ NMR spectroscopy. The $\mathrm{NHs}$ in the bound-chloride receptors are the most downfield shifted signals of the spectrum and resonate completely separate of any other proton signal. We observed two different sets of signals for the NHs corresponding to each one of the complexes. In addition, the ${ }_{31} \mathrm{P}\{1 \mathrm{H}\}$ NMR spectrum displayed different signals for the phosphorus atoms of the two receptors, both in the free and bound state (Figure $7 \mathrm{~b}$ ). The integral values of the $\mathrm{NH}$ proton signals for each receptor, in both free and bound state, were used to calculate the ratio of association constants. In good agreement with the ITC results we determined that Ka, $\exp (9 \subset 70000) / \mathrm{Ka}, \exp (9 \subset 7 i o o o) \approx 4$. Previous studies with bis-phosphonate calix[4]pyrroles 2, had shown that the inward orientation of one $\mathrm{P}=\mathrm{O}$ group produced an energetic disadvantage to a similar extent.16 We hypothesized that the existence of repulsive electrostatic interactions between the negative end of the dipole moment of the inwardly directed $\mathrm{P}=\mathrm{O}$ group and the included chloride was responsible of the reduction in binding affinity.

The calix[4]pyrrole cavitand 8 (Scheme 2) was used as model system to quantify the electrostatic effect provided by the four phosphonate groups in the $9 \subset 70000$ complex. ITC experiments assigned a stability constant of $0.2 \pm 0.1 \times 107 \mathrm{M}-1$ to the $9 \subset 8$ complex. This value is approximately 8 o fold smaller (two orders of magnitude) than the one calculated for the $9 \subset 70000$ complex. Therefore, the stabilizing electrostatic effect provided by the four phosphonate group was quantified to be $\sim-2.5 \mathrm{kcal} / \mathrm{mol}$. This value nicely doubles the $-1.4 \mathrm{kcal} / \mathrm{mol}$ calculated for the introduction of two $\mathrm{P}=\mathrm{O}$ groups in the bisphosphonate cavitands 2.16

Interestingly, receptor 70000 was also very effective in $\mathrm{CH}_{2} \mathrm{Cl}_{2}$ solution for the complexation of acetylcholine chloride (11, Figure 6), a bio-relevant trimethyl-alkylammonium salt. , Using 1 H NMR spectroscopy, we estimated a stability constant value larger than 104 M-1 for the 1:1 complex $11 \subset 70000$. The analysis of the 1 H NMR titration data assigned a host-separated geometry for the ion-pair in the complex. One of the methyl groups in the trimethylammonium knob of the acetylcholine can be accommodated easily by the shallow aromatic $\pi$-cavity provided by the calix[4]pyrrole core opposite to the deep included chloride (SI).

Comparison of the binding affinity of tetra-phosphonate 70000 vs bis-phosphonate 200 towards TMPCl. The ratio of the stability constants determined from ITC experiments

$\mathrm{Ka}, \exp (9 \subset 70000) / \mathrm{Ka}, \exp (9 \subset 200) 16$ is $\approx 200$. To further verify the energetic advantage provided by the introduction of two additional phosphonate groups, we performed a direct competitive binding experiment between the 70000 and 200 receptors. The analysis of a $\mathrm{CD}_{2} \mathrm{Cl}_{2}$ solution containing an equimolar mixture of the two receptors and TMPCl using ${ }_{1} \mathrm{H}$ NMR and ${ }_{31} \mathrm{P}\{1 \mathrm{H}\}$ NMR revealed the exclusive formation of $9 \subset 70000$ (Figure S12). Consequently, and in complete agreement with the ITC results, the value of the Ka,exp $(9 \subset 70000)$ is more than two orders of magnitude larger than $\mathrm{Ka}, \exp (9 \subset 200)$. The measured difference in binding affinities is greater than expected for the electrostatic gain provided by the introduction of two additional $\mathrm{P}=\mathrm{O}$ groups $(-1.4 \mathrm{kcal} / \mathrm{mol}$, corresponding to a 10 fold increase in binding affinity). The superior binding properties displayed by the tetra-phosphonate calix[4]pyrrole 70000 for the complexation of $\mathrm{TMPCl}$, in comparison to the bisphosphonate 200 counterpart, resulted from the combination of an increase in the number of favorable electrostatic interactions and the reduction of conformational flexibility. In short, the tetraphosphonate isomer 70000 shows superior binding properties for TMPCl than the bis-phosphonate analog 200 . 
Effect of hydrogen bonding as an additional driving force for the recognition of primary ammonium salts and switching of the ion-pair binding mode. The iiii stereoisomer of tetra-phosphonate resorcin [4]arene cavitands and other phosphonate derivatives with at least one $\mathrm{P}=\mathrm{O}$ group inwardly directed are known to interact with primary alkylammonium cations by establishing simultaneously $\mathrm{NH}$... O hydrogen bonds and cation-dipole inter-actions.25, We became interested in assessing the effect provided by one inwardly oriented $\mathrm{P}=\mathrm{O}$ group on the complexation of a primary ammonium salt i.e. oc-tylammonium chloride (OAMCl, 10, Figure 6) by the tet-ra-phosphonate calix[4]pyrrole 7iooo cavitand. We learned from previous studies with the series of bis-phosphonate calix[4]pyrrole cavitands 2 that octylammonium chloride 1o formed a 1:1 complex with the zio isomer that was approximately two-fold thermodynamically more stable than the analogous complex with the 200 isomer. In addition, while the $10 \subset 200$ complex showed in solution a receptor-separated binding mode, the 2 io isomer bound the primary salt 10 in a close-contact geometry. That is, the chloride was included in the deep aromatic cavity of zio and the cobound cation was located close to the upper rim, establishing a combination of ion-dipole and hydrogen bond interactions with the inwardly oriented $\mathrm{P}=\mathrm{O}$ group.

Pairwise competitive experiment carried out in $\mathrm{CD}_{2} \mathrm{Cl}_{2}$ solution between the diastereoisomers 70000 and 7iooo towards 10 (Figure S21) uncovered an analogous trend in stability constants for the tetraphosphonate series binding a primary ammonium chloride, that is $\mathrm{Ka}, \exp (10 \subset 7 \mathrm{iooo}) \approx 2$

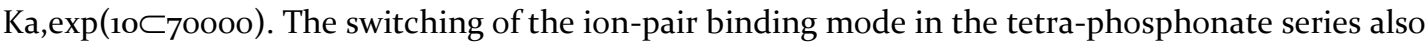
became evident by comparison of the complexation induced shift experienced by methylene protons $\alpha$ to the nitrogen atom in the bound octylammonium cation, $\Delta \delta=-0.45 \mathrm{ppm}$ and $\Delta \delta=-2.2 \mathrm{ppm}$ for $10 \subset 7$ iooo and $10 \subset 70000$ respectively. The highest upfield shift of the methylene protons $\alpha$ to the nitrogen atom in the 10 ? 70000 complex is caused by their preferential inclusion in the shallow cup-like of the calix[4]pyrrole opposite to the bound chloride (host-separated binding mode, Figure 9).

Figure 9.

A direct competition experiment performed between the best receptors of the bis- and tetraphosphonate series, $2 \mathrm{ii}$ and 7 iooo respectively; towards the octylammonium chloride 10 assigned a twofold thermodynamic advantage to the 10国ii complex (Figure S22). A similar experiment performed between zio and 7iooo (Figure S23) established a superior binding ability of the tetra-phosphonate

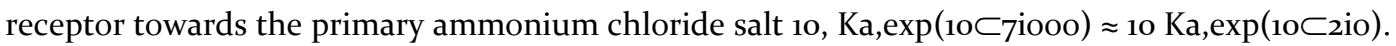
Taking together, these results demonstrated that the reduction of conformational flexibility and the presence of additional outwardly oriented $\mathrm{P}=\mathrm{O}$ groups featured by the tetra-phosphonate receptors, compared to the bis-phosphonate analogs, increased the binding affinity towards ion-pair 1o. However, these two effects were not enough to outperform the inward orientation of two $\mathrm{P}=\mathrm{O}$ groups present in the zii diastereoisomer. Therefore, the synthesis of tetra-phosphonate isomers featuring more than one $\mathrm{P}=\mathrm{O}$ group inwardly oriented may lead to the discovery of calix[4]pyrrole receptors with superior binding properties than the bis-phosphonate isomer zii towards primary ammonium ion-pairs.

Effect of the solvent in the selective binding of TMPCl by tetra- vs bis-phosphonate receptors. It is well known that the nature of the solvent has a strong impact on the behavior of the salts in solution. In low permittivity media (i.e $\mathrm{CH}_{2} \mathrm{Cl}_{2}$ ), ion-pair formation is likely to occur. Conversely, in high permittivity solvents (i.e. $\mathrm{CH}_{3} \mathrm{CN}$ ), alkylphosphonium salts at $1 \mathrm{mM}$ concentration are expected to be fully dissociated. Owing to solubility reasons, we could only investigate the binding of $\mathrm{TMPCl}$, 9, with the 70000 isomer in $\mathrm{CD}_{3} \mathrm{CN}$ solution. The 7iooo was not soluble in $\mathrm{CD}_{3} \mathrm{CN}$ at the concentration required to perform NMR experiments. The interaction of the receptor 7oooo with 9 was probed using IH NMR spectroscopy. The results obtained indicated: a) the existence of a chemical exchange between 
the free and bound receptor that was slow on the chemical shift timescale, and b) the formation of a 1:1 anionic complex $\mathrm{Cl}^{-} \subset 70000$ with a sta-bility constant that was estimated to be higher than $104 \mathrm{M}-1$ (See Supporting Information). The lack of involvement of the cation in the anionic complex $\mathrm{Cl}^{-} \subset 70000$ was inferred from the absence of complexation induced changes in the proton signals of the TMP. A pairwise competitive experiment performed with receptors 70000 and 200 towards 9 in $\mathrm{CD}_{3} \mathrm{CN}$ allowed the determination of the ratio of the stability constants of the corresponding chloride complexes as: $\mathrm{Ka}, \exp \left(\mathrm{Cl}^{-} \subset 7 \mathrm{Oooo}\right) / \mathrm{Ka}, \exp \left(\mathrm{Cl}^{-} \subset 200\right) \approx 6$, a value that gauges the energy gain provided by the conformational rigidification of the receptor and the introduction of two additional $\mathrm{P}=\mathrm{O}$ groups. Interestingly, the same ratio of stability constants determined above in $\mathrm{CD}_{2} \mathrm{Cl}_{2}$ solu-tion is approximately 200 . The measured difference in the values of the constant ratios indicated that the binding of the TMP cation occurring in low polarity solvents, which afforded ion-paired complexes with the same binding mode, is not isoenergetic for the tetra and bis-phosphonate cavitands. The recognition of the TMP cation seems to be the determining step for the high selectivity for 70000 towards TMPCl measured in $\mathrm{CD}_{2} \mathrm{Cl}_{2}$. This finding is in complete agreement with recent computational studies on bis-phosphonate calix[4]pyrrole cavitands 2. Taking as reference the value of $\mathrm{Ka}, \exp \left(\mathrm{Cl}^{-} \subset 200\right)=6.0 \pm 2 \times 103 \mathrm{M}-1$ determined in a previous work,16 we calculated a stability constant value $\mathrm{Ka}, \exp \left(\mathrm{Cl}^{-} \subset 7 \mathrm{OOOO}\right)=3.6 \times 104 \mathrm{M}-1$ in acetonitrile. Not surprisingly, the stability constant determined for the 1:1 anionic complex that is formed in the polar solvent is reduced by three orders of magnitude compared to the one calculated for the 1:1 ion-paired counterpart $\mathrm{Ka}, \exp (9 \subset 70000)=16.0 \pm 5 \times 107 \mathrm{M}-1$ in $\mathrm{CD}_{2} \mathrm{Cl}_{2}$ solution. In short, the nature of the solvent has a strong impact in both binding affinity and characteristics of the complex.

\section{Conclusions}

We have synthesized two unprecedented diastereoiso-meric tetra-phosphonate cavitands 70000 and 7iooo based on a calix[4]pyrrole octol scaffold $6 \mathrm{~b}$. The solid-state structures available for phosphonate resor-cin[4]arene cavitands and the X-ray structures reported here for tetra-phosphonate calixpyrrole cavitands re-vealed significant differences in the conformations adopted by their phosphocine rings. The eight-membered phosphocine rings present in the phosphonate resorcin[4]arene cavitands always adopted a boat-chair conformation. In contrast, the fourteen-membered phosphocine ring of the calix[4]pyrrole phosphonate cavitands is conformationally flexible. Two different low energy conformations, boat-chair and boat-twistboat, are observed in response to the relative orientation of the $\mathrm{P}=\mathrm{O}$ group with respect to the aromatic cavity. Interestingly, in both of them, the phenyl group is oriented in an equatorial position pointing away from the aromatic cavity. The com-plexation of tetramethylphosphonium chloride by the tetra-phosphonate calix[4]pyrrole receptors 70000 and 7 iooo was probed using NMR spectroscopy both in $\mathrm{CH}_{2} \mathrm{Cl}_{2}$ and $\mathrm{CH}_{3} \mathrm{CN}$ solutions. In $\mathrm{CH}_{2} \mathrm{Cl}_{2}$ solution ionpaired complexes $9 \subset 7$ with 1:1 stoichiometry are formed, in which the ion-pair displayed a hostseparated binding mode independent of the relative orientation of the $\mathrm{P}=\mathrm{O}$ groups. Using ITC experiments we assessed accurately the binding constant values of TMPCl with the two tetraphosphonate calix[4]pyrrole diastereoisomers. The 70ooo receptor showed higher affinity, most likely due to the existence of repulsive interactions between the negative end of the dipole moment of the inwardly directed $\mathrm{P}=\mathrm{O}$ in 7iooo and the included chloride. Interestingly, the complexation of the primary ammonium chloride 10 by the tetra-phosphonate isomers 7 featured a switching of the ionpair binding mode. The receptor 7oooo bound to in host separated mode, while jiooo produced a close-contact arrangement of the ions in the complex. This behavior demonstrated the use of the tetraphosphonate cavitands 7 as multitopic receptors. Owing to reduction in conformation flexibility and increase of electrostatic interactions the tetra-phosphonate isomers 7 outperformed their bisphosphonate analogues 2 (2io and 200) in the binding of 10. However, the zii isomer still showed a superior binding affinity for 10 than 7iooo. Binding experiments performed in $\mathrm{CH}_{3} \mathrm{CN}$ with the 70000 receptor and TMPCl revealed the formation of anionic complexes $\mathrm{Cl}^{-} \subset 7000$. The comparison of the stability constants determined for the $\mathrm{Cl}^{-} \subset 70000\left(\mathrm{CH}_{3} \mathrm{CN}\right)$ and $\mathrm{TMPCl} \subset 70000\left(\mathrm{CH}_{2} \mathrm{Cl}_{2}\right)$ complexes 
indicated that ion-pair binding is determinant for the high selectivity exhibited by this receptor in nonpolar solvents towards TMPCl.

\section{ASSOCIATED CONTENT}

Supporting Information.

Experimental procedures for the synthesis of the cavitands and their characterization data; ${ }_{1} \mathrm{H}$ and ${ }_{31} \mathrm{P}$ NMR spectra of the binding studies of 7 and 8 with TMPCl; competitive ex-periments performed in both dichloromethane and acetoni-trile solutions between the two diastereoisomers 7 , as well as with the bis-phosphonate calix[4]pyrroles 2; ITC experiments of 7 with $\mathrm{TMPCl}$; ${ }_{1} \mathrm{H}$ and ${ }_{31} \mathrm{P}$ NMR spectra of the binding studies of 7 with acetylcholine chloride; ESI-MS experiments; conformational studies of resorcinarene cavitands 4; computational studies details and coordinates of the energy minimized structures. This material is available free of charge via the Internet at http://pubs.acs.org

\section{AUTHOR INFORMATION}

Corresponding Author

pballester@iciq.es

Notes

The authors declare no competitive financial interest

Present Addresses

†Moira Ciardi: Université catholique de Louvain, Institute of Condensed Matter and Nanosciences, Croix du Sud, 1

B-1348 Louvain-la-Neuve

\section{ACKNOWLEDGMENT}

The authors thank Spanish Ministerio de Economı y Com-petitividad (CTQ2011-23014), Generalitat de Catalunya(2014 SGR 320 ), Gobierno de España MINECO (project CTQ2011-23014), Severo Ochoa Excellence Accreditation 2014-2018 (SEV-2013-0319), and the ICIQ Foundation for funding. A.G. thanks MINECO for a FPU fellowship. We thank Eduardo C. Escudero-Adán for X-Ray crystallographic data.

\section{REFERENCES}

Kim, S. K.; Sessler, J. L. Chem. Soc. Rev. 2010, 39, 3784-3809.

McConnell, A. J.; Beer, P. D. Angew. Chem., Int. Ed. 2012, 51, 5052-5061.

Howe, E. N. W.; Bhadbhade, M.; Thordarson, P. J. Am. Chem. Soc. 2014, 136, 7505-7516.

Kim, S. K.; Sessler, J. L. Acc. Chem. Res. 2014, 47, 2525-2536.

Howe, E. N. W.; Bhadbhade, M.; Thordarson, P. J. Am. Chem. Soc. 2014, 136, 7505-7516.

Fasting, C.; Schalley, C. A.; Weber, M.; Seitz, O.; Hecht, S.; Koksch, B.; Dernedde, J.; Graf, C.; Knapp, E. W.; Haag, R. Angew Chem Int Edit 2012, 51, 10472-10498.

Hunter, C. A.; Anderson, H. L. Angew Chem Int Edit 2009, 48, 7488-7499.

Ercolani, G.; Schiaffino, L. Angew Chem Int Edit 2011, 50, 1762-1768. 
Perraud, O.; Robert, V.; Martinez, A.; Dutasta, J. P. Chem.--Eur. J. 2011, 17, 4177-4182.

Gibson, H. W.; Jones, J. W.; Zakharov, L. N.; Rheingold, A. L.; Slebodnick, C. Chem.--Eur. J. 2011, 17, 3192-3206.

Shukla, R.; Kida, T.; Smith, B. D. Org. Lett. 2000, 2, 3099-3102.

Roelens, S.; Vacca, A.; Francesconi, O.; Venturi, C. Chem.--Eur. J. 2009, 15, 8296-8302.

Park, I. W.; Yoo, J.; Kim, B.; Adhikari, S.; Kim, S. K.; Yeon, Y.; Haynes, C. J. E.; Sutton, J. L.; Tong, C. C.; Lynch, V. M.; Sessler, J. L.; Gale, P. A.; Lee, C. H. Chem.--Eur. J. 2012, 18, 2514-2523.

Park, I. W.; Yoo, J.; Adhikari, S.; Park, J. S.; Sessler, J. L.; Lee, C. H. Chem.--Eur. J. 2012, 18, 15073-15078.

Kim, S. K.; Lynch, V. M.; Young, N. J.; Hay, B. P.; Lee, C. H.; Kim, J. S.; Moyer, B. A.; Sessler, J. L. J. Am. Chem. Soc. 2012, 134, 20837-20843.

Ciardi, M.; Tancini, F.; Gil-Ramirez, G.; Escudero-Adan, E. C.; Massera, C.; Dalcanale, E.; Ballester, P. J. Am. Chem. Soc. 2012, 134, 13121-13132.

Delangle, P.; Dutasta, J. P. Tetrahedron Lett. 1995, 36, 9325-9328.

Jacopozzi, P.; Dalcanale, E.; Spera, S.; Chrisstoffels, L. A. J.; Reinhoudt, D. N.; Lippmann, T.; Mann, G. J. Chem. Soc., Perkin Trans. 2 1998, 671-677.

Delangle, P.; Mulatier, J.-C.; Tinant, B.; Declercq, J.-P.; Dutasta, J.-P. Eur. J. Org. Chem. 2001, 36953704 .

Xu, W.; Rourke, J. P.; Vittal, J. J.; Puddephatt, R. J. Inorg. Chem. 1995, 34, 323-329.

Yebeutchou, R. M.; Tancini, F.; Demitri, N.; Geremia, S.; Mendichi, R.; Dalcanale, E. Angew. Chem., Int. Ed. 2008, 47, 4504-4508.

Kalenius, E.; Neitola, R.; Suman, M.; Dalcanale, E.; Vainiotalo, P. J. Am. Soc. Mass Spectrom. 2010, 21, 440-450.

Biavardi, E.; Tudisco, C.; Maffei, F.; Motta, A.; Massera, C.; Condorelli, G. G.; Dalcanale, E. Proc. Natl. Acad. Sci. U. S. A. 2012, 109, 2263-2268.

Kalenius, E.; Moiani, D.; Dalcanale, E.; Vainiotalo, P. Chem. Commun. 2007, 3865-3867.

Pinalli, R.; Dalcanale, E. Acc. Chem. Res. 2013, 46, 399-411.

Slovak, S.; Evan-Salem, T.; Cohen, Y. Org. Lett. 2010, 12, 4864-4867.

Galan, A.; Escudero-Adan, E. C.; Frontera, A.; Ballester, P. J. Org. Chem. 2014, 79, 5545-5557.

The exchange process between free and bound TMPCl when an excess of salt is present is fast in the NMR timescale. This confirms the existence of two different exchange processes in solution. The exchange of the bound cation by another molecule of TMP takes place directly, whereas the exchange of the bound anion by another chloride or by a solvent molecule requires a conformational change in the calix[4]pyrrole receptor.

The kinetic and thermodynamic behavior of the complexation process of TMPCl with 8 was also studied using NMR spectroscopy (See Supporting Information). The obtained results are analogous to those described for the tetra-phosphonate stereoisomers. 
An, M. C.; Lin, W. C.; Yang, J. F.; Dominguez, B.; Padgett, D.; Sugiura, Y.; Aryal, P.; Gould, T. W.; Oppenheim, R. W.; Hester, M. E.; Kaspar, B. K.; Ko, C. P.; Lee, K. F. Proc. Natl. Acad. Sci. U. S. A. 2010, 107, 10702-10707.

Ragozzino, M. E.; Unick, K. E.; Gold, P. E. Proc. Natl. Acad. Sci. U. S. A. 1996, 93, 4693-4698.

Lippmann, T.; Wilde, H.; Dalcanale, E.; Mavilla, L.; Mann, G.; Heyer, U.; Spera, S. J. Org. Chem. 1995, 6o, 235-242.

Wang, T.; Liu, J.; Sun, H.; Chen, L.; Dong, J.; Sun, L.; Bi, Y. RSC Adv. 2014, 4, 1864-1873. 
Figure 1. Line drawing structures and schematic representa-tion of multitopic receptors: a) compound 1 described by Sessler et al.15 and b) bis-phosphonate cavitands 2 reported by our group. In both receptors, the different binding sites for the cation are highlighted with blue ribbons. The close-contact binding mode (right) and the host-separated ar-rangement (left) of the ion-pair are shown for the complexes with 2.

a)

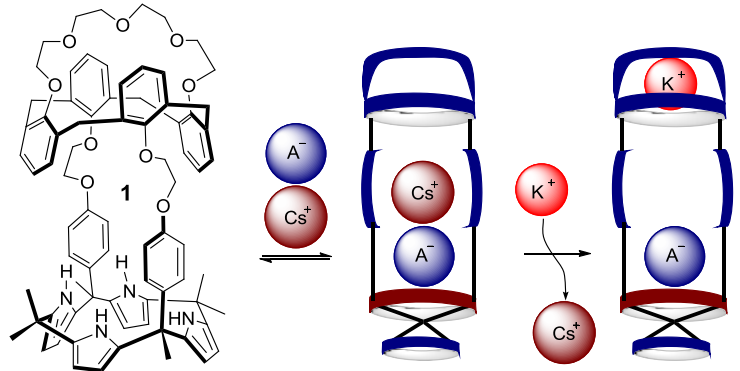

b)

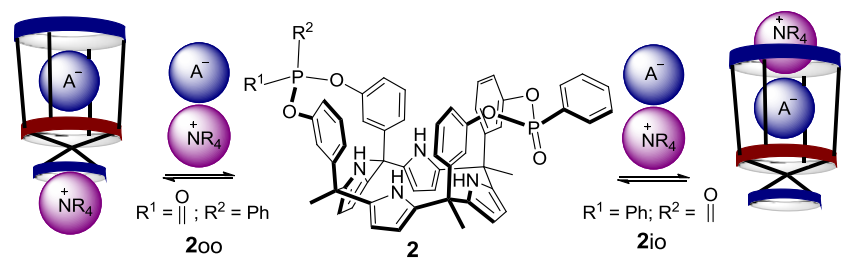

Scheme 1. Reaction scheme for the preparation of tetra-phosphonate resorcinarene cavitands 4.
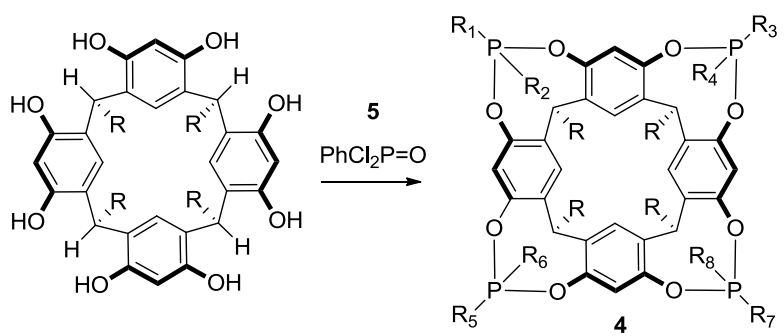

$3 \mathrm{R}=\mathrm{CH}_{3}$

\begin{tabular}{|c|c|c|c|c|c|}
\hline & ${ }_{1}=R_{7}$ & $R_{2}=R_{8}$ & $R_{3} R_{4}$ & $R_{5} R_{6}$ & 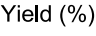 \\
\hline 40000 & $=0$ & $\mathrm{Ph}$ & $=0 \mathrm{Ph}$ & $=0 \mathrm{Ph}$ & 2 \\
\hline 4iioo & $\mathrm{Ph}$ & $=0$ & $=0 \mathrm{Ph}$ & $=O \mathrm{Ph}$ & 5 \\
\hline $4 \mathrm{iooo}$ & $=0$ & $\mathrm{Ph}$ & $=0 \mathrm{Ph}$ & $\mathrm{Ph}=0$ & 15 \\
\hline \multicolumn{6}{|c|}{$\mathrm{R}_{1}=\mathrm{R}_{3} \quad \mathrm{R}_{2}=\mathrm{R}_{4}$} \\
\hline
\end{tabular}


Scheme 1 Reaction scheme for the preparation of tetra-phosphonate cavitands 7 based on a calix[4]pyrrole octol scaffold.

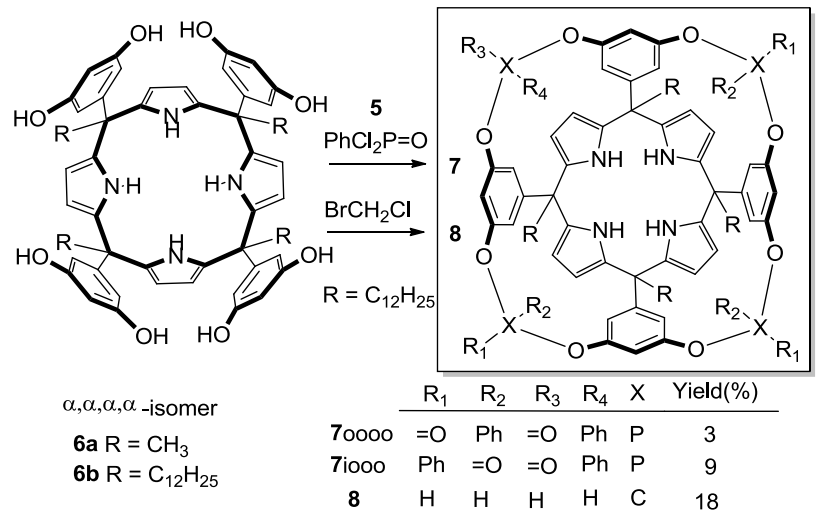

Figure 2. Selected regions of $1 \mathrm{H}$ and $31 \mathrm{P}\{1 \mathrm{H}\}$ NMR spectra of a $\mathrm{CD} 2 \mathrm{Cl} 2$ solution of tetraphosphonate 70000 . Inset: line drawing structure of 70000 indicating the proton assign-ment.

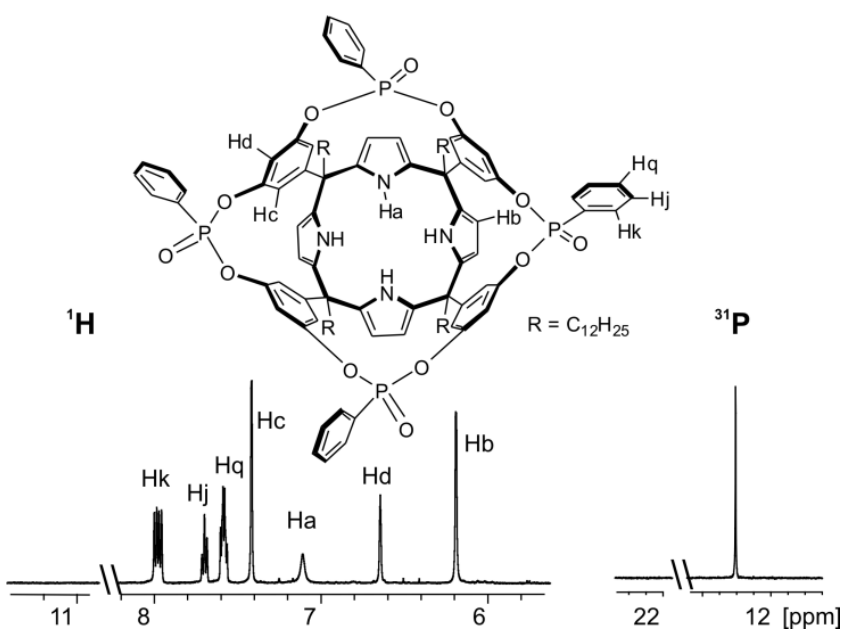


Figure 3. Equilibria involving the two possible conformers, boat-twistboat and boat-chair, of the fourteen-membered phosphocine rings present in the stereoisomers of bis- and tetraphosphonate calix[4]pyrrole cavitands. Top: $\mathrm{P}=\mathrm{O}$ out(o); Bottom: $\mathrm{P}=\mathrm{O}$ in(i). Notice that the preferred confor-mation of the ring is dictated by the equatorial position of the phenyl group.

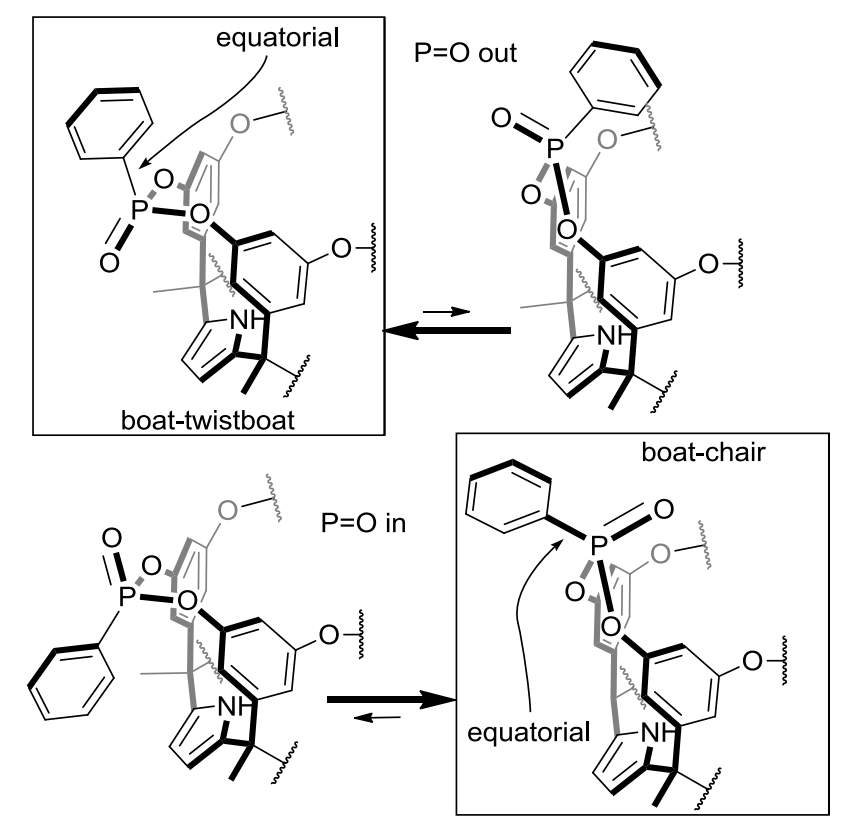


Figure 4. Side and top views of the X-ray structure of tetra-phosphonate 70000 (C4 symmetry). Solvent molecules and non-polar hydrogen atoms are removed. Dodecyl chains are pruned for clarity. The depicted cyclochiral enantiomer is assigned $\mathrm{M}$ configuration.

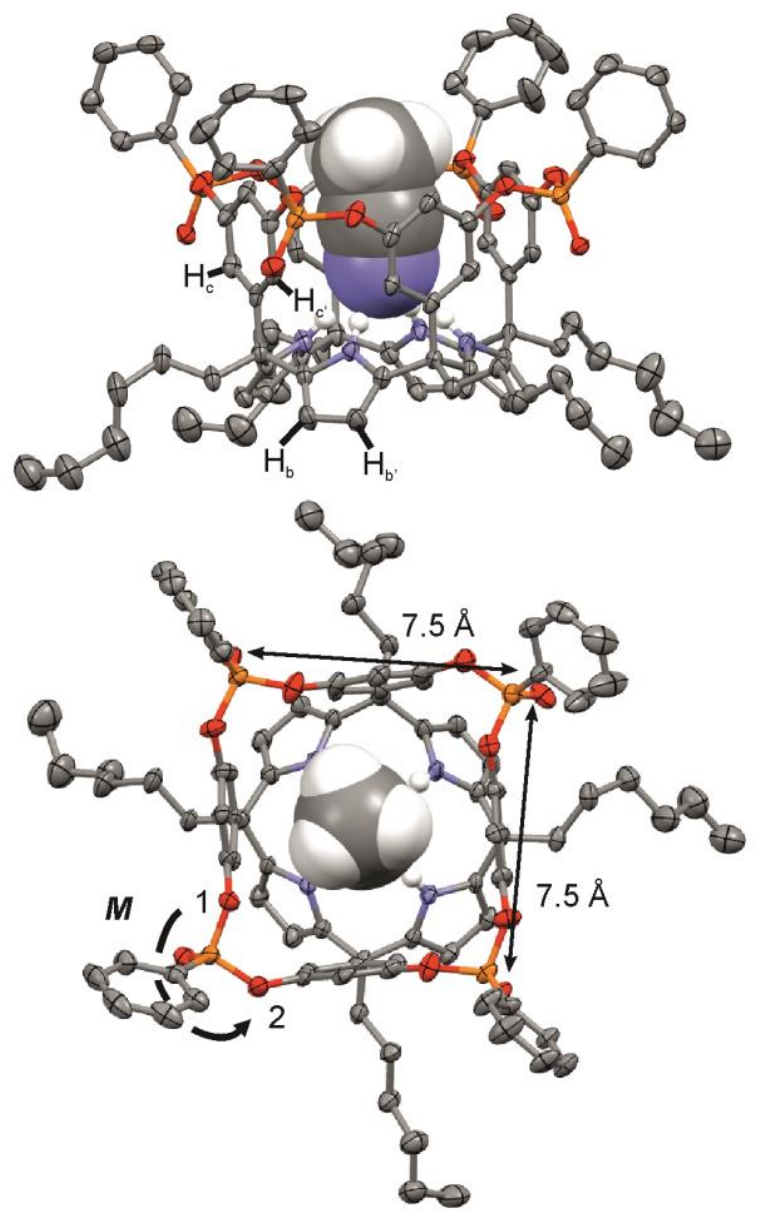

Figure 5. Selected regions of $1 \mathrm{H}$ and $31 \mathrm{P}\{1 \mathrm{H}\}$ NMR of a $\mathrm{CD} 2 \mathrm{Cl} 2$ solution of tetra-phosphonate 7iooo. Inset: line drawing structure of 7iooo indicating the proton assignment.

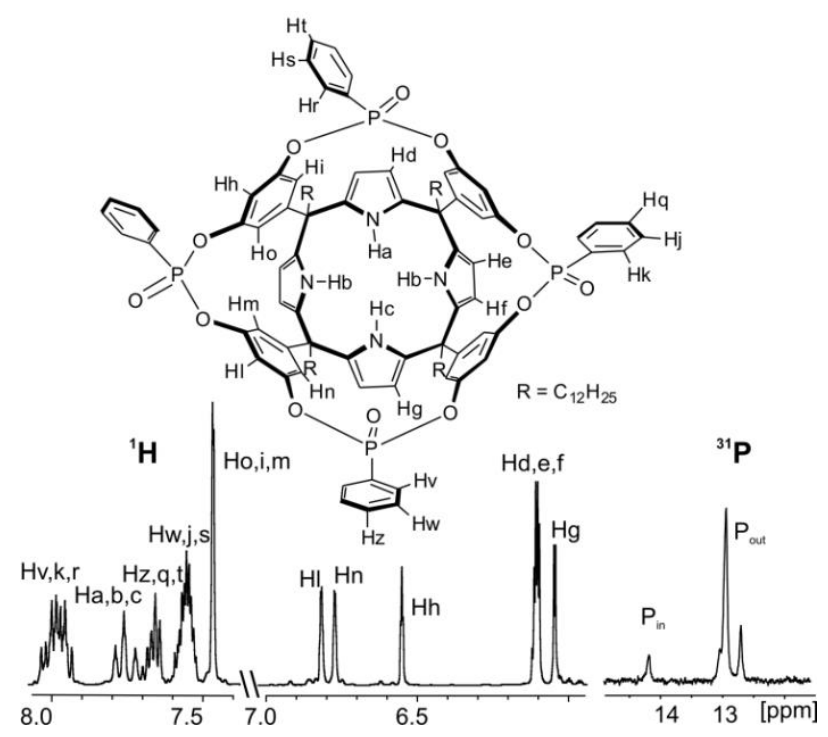


Figure 6. Line drawing structures of the phosphonium and ammonium chloride salts used in this study.

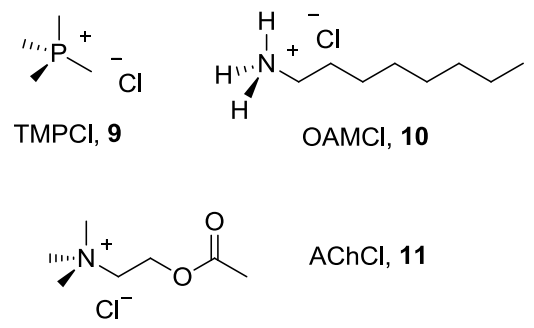

Figure 7. Selected regions of the $1 \mathrm{H}$ and $31 \mathrm{P}\{1 \mathrm{H}\}$ NMR spectra in $\mathrm{CD} 2 \mathrm{Cl} 2$ solution of equimolar mixtures of a) 70000 and 9, b) 70000, 7iooo and 9 c) 7iooo and 9. Primed letters indicate the signals corresponding to the protons involved in complex formation. See Figure 2 and Figure 5 for proton assignment.
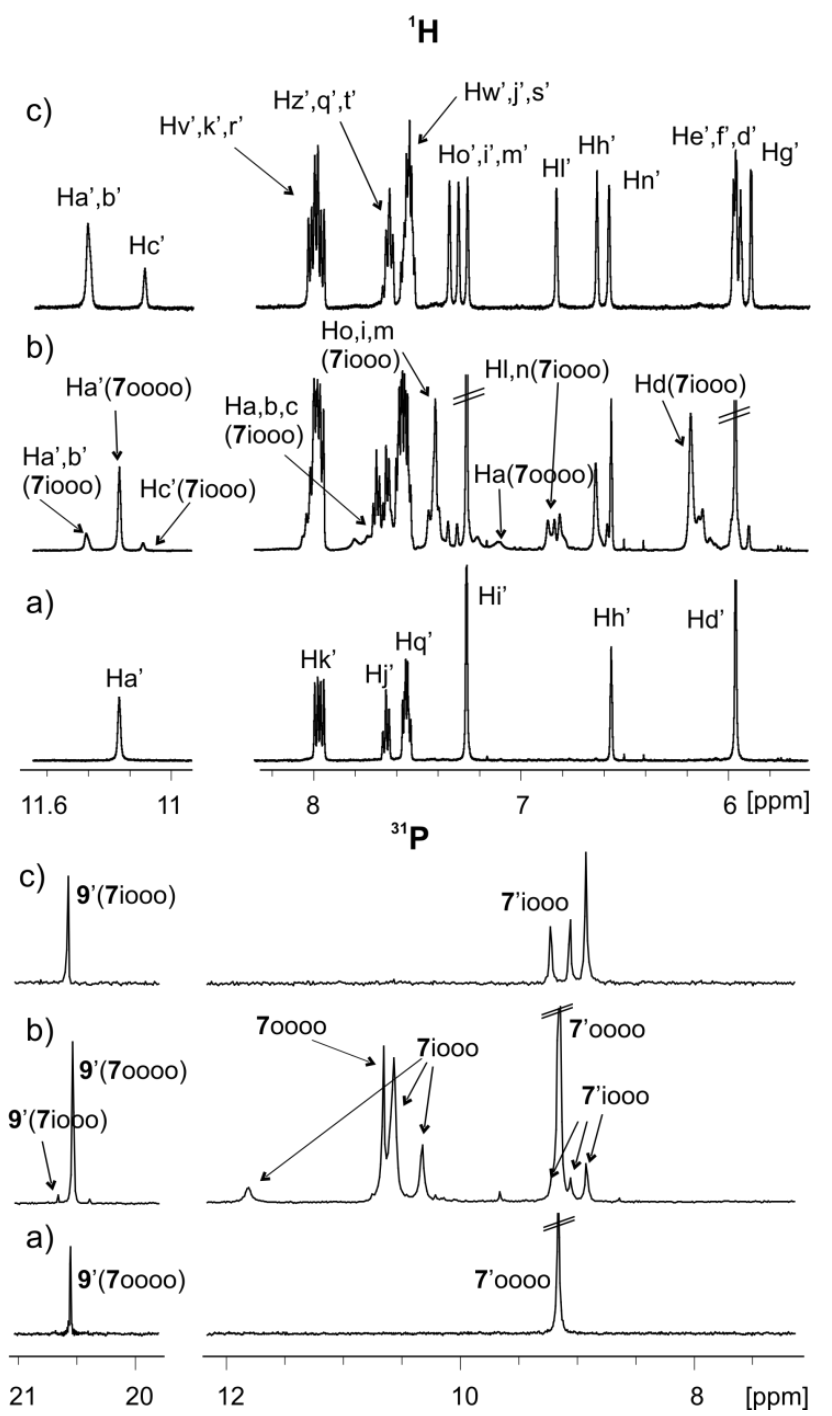
Figure 8. Solid-state structure of the complex 907iooo. The cavitand is depicted in stickellipsoid style at $50 \%$ probability level for all atoms whereas the TMPCl salt is shown as spacefill model.

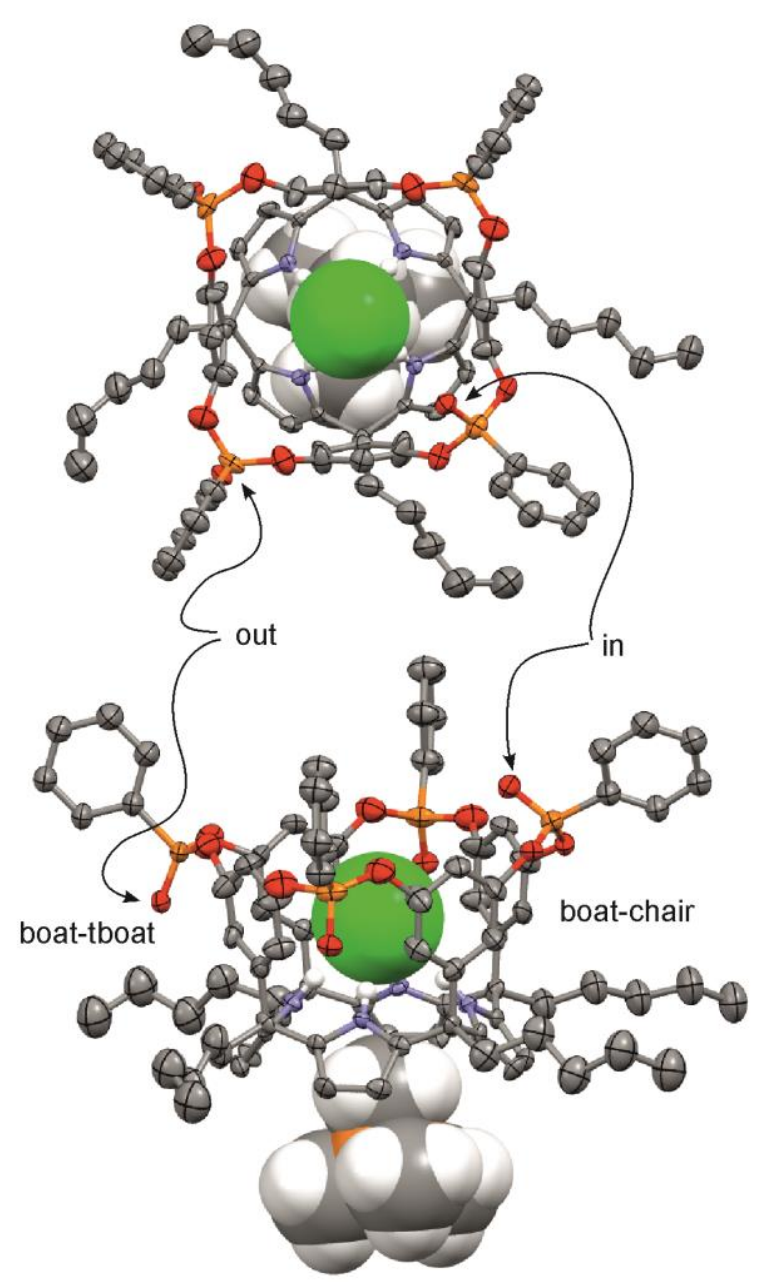

Table 1. Stability constant values ( $\mathrm{Ka}, \mathrm{M}-1$ ), free ener-gies of binding (G $\mathrm{G}, \mathrm{kcal} / \mathrm{mol}$ ),

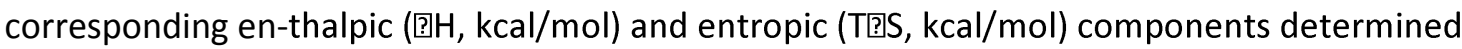
for the 1:1 complexes of TMPCI 9 with diastereomeric tetra-phosphonates 70000, 7iooo and cavitand 8 in dichloromethane so-lution (298K).

\begin{tabular}{|l|l|l|l|l|}
\hline Receptor & $K_{\mathrm{a}} \times 10^{-7}$ & $\Delta G$ & $\Delta H$ & $\mathrm{~T} \Delta \mathrm{S}$ \\
\hline 70000 & $16.0 \pm 5$ & $-11.2 \pm 0.2$ & $-7.2 \pm 0.1$ & $4.0 \pm 0.2$ \\
\hline 7iooo & $3.3 \pm 1.1$ & $-10.2 \pm 0.2$ & $-5.7 \pm 0.1$ & $4.5 \pm 0.2$ \\
\hline $\mathbf{8}$ & $0.2 \pm 0.1$ & $-8.5 \pm 0.3$ & $-3.3 \pm 0.1$ & $5.2 \pm 0.3$ \\
\hline
\end{tabular}


Figure 9. Energy-minimized structures at the BP86/dev2-SVP level of theory of the complexes:

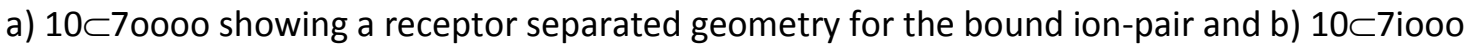
featuring close-contact arrangement of the ion pair. The $\mathrm{P}=0$ group inwardly oriented in $10 \subset 7$ iooo is hydrogen bonded to the OAM cation. The octyl substituent in 10 was modelled as a propyl residue and the meso-dodecyl chains in 7 as methyl groups to reduce calculation time.

a)

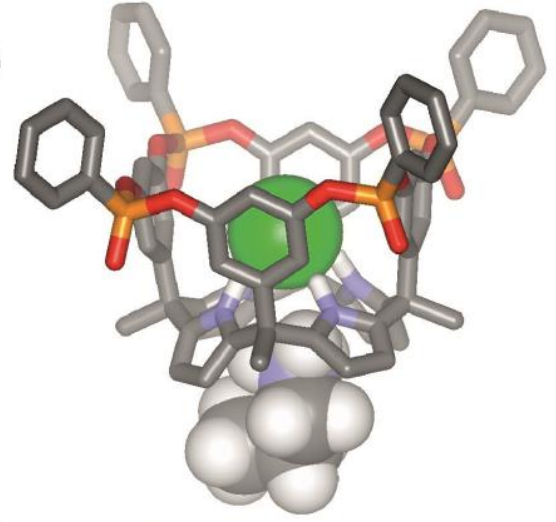

b)

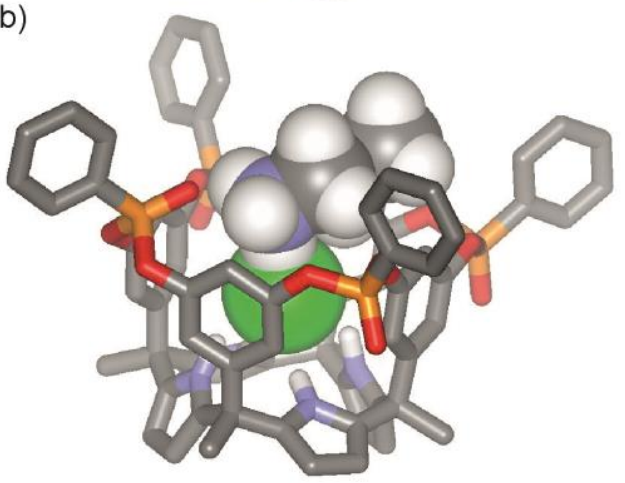

TOC

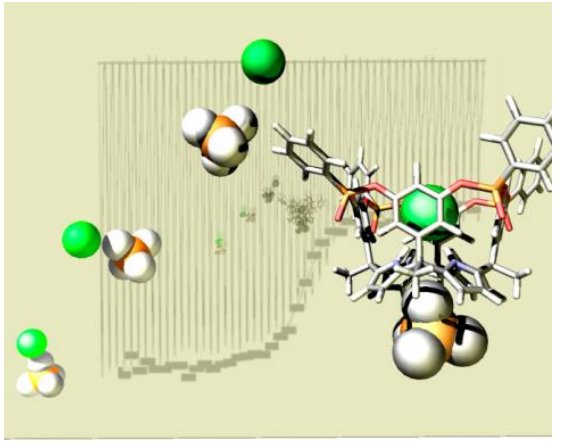

